\title{
¿EXPERIENCIAS DE SEGREGACIÓN O ACOSO EN LA MAQUILADORA? TESTIMONIOS DE TRABAJADORES(AS) EN Ciudad Juárez, Chihuahua
}

\author{
MYRNA LIMAS HERNÁNDEZ ${ }^{1}$ \\ FERNANDA NOHEMÍ FRÍAS MARTÍNEZ ${ }^{2}$
}

\section{RESUMEN}

U

na tarea clave que inició el Instituto Nacional de las Mujeres del gobierno mexicano en la década 2000 fue certificar empresas según el Modelo de Equidad de Género (MEG), ante el compromiso de cumplir con acuerdos internacionales en aras de propiciar ambientes laborales libres de violencia de género y promover la equidad e igualdad de oportunidades. El objetivo en este artículo es exponer algunas experiencias de empleados(as) de una empresa maquiladora certificada en tal modelo, enmarcando dos ejes: segregación laboral por razones de género y acoso/ hostigamiento sexual. El trabajo en campo consistió en realizar entrevistas durante mayo y junio de 2017. El análisis se enfoca en seis categorías: discriminación, puestos y salarios, relaciones per-

1 Docente investigadora de tiempo completo en la Universidad Autónoma de Ciudad Juárez. Correo: mlimas@uacj.mx

2 Docente por honorarios en la Licenciatura en Educación en la UACJ y docente por honorarios en el programa de Psicología en la Universidad Tecnológica de Ciudad Juárez. Correo: pakky14@hotmail.com 
sonales, conocimiento y percepción del tema, eventos de acoso, y atención y seguimiento a denuncias.

Palabras clave: certificación de género, segregación laboral, acoso y hostigamiento sexual, grupos vulnerables, Ciudad Juárez.

\begin{abstract}
A key issue that began the Mexican government's National Women Institute in the 2000s was to certify companies according to the Gender Equity Model (GEM), in the fase of a commitment to comply with international agreements, to fostering work environments free of gender-based violence and promoting equity and equal opportunities. The objective in this paper is to expose some experiences of employees of a maquiladora company certified in such a model, framing two axes: labor segregation for reason of gender and sexual harassment/harassment. The field research required interviewing six workers in may and june 2017. The analysis focuses in six different categories: discrimination, positions and salaries, personal relationships, knowledge and perception of the subject, harassments events, and, attention and follow-up to complaints.
\end{abstract}

Key words: gender certification, labor segregation, sexual harassment, vulnerable groups, Juarez City

\title{
INTRODUCCIÓN ${ }^{3}$
}

Un Objetivo de Desarrollo Sostenible de las Naciones Unidas (el número 5) busca "Lograr la igualdad entre los géneros y empoderar a todas las mujeres y las niñas” para evitar ambientes de violencia y discriminación en el mundo (un.org/sustainabledevelopment, 2020). Una propuesta planteada desde el Programa de Desarrollo

3 Se agradece de manera especial la colaboración del doctor Alfredo Limas Hernández y al prestador de servicio social Pedro Noé Gutiérrez Tena por sus aportaciones y revisiones en la integración de este documento. 
de las Naciones Unidas (PNUD) para incentivar condiciones igualitarias entre hombres y mujeres es solicitar a los gobiernos de los países implementar el denominado "Sello de igualdad de género" como parte del Programa de certificación para que instituciones públicas y privadas participantes contribuyan a reducir desigualdades en el trabajo, promover buenas prácticas e impulsar la cooperación sur-sur.

El Sello de igualdad de género tiene su origen en América Latina. El PNUD estima que desde 2009 se han certificado más de 400 instituciones en 10 países (un.org). En el caso de México, el Instituto Nacional de las Mujeres (Inmujeres) del gobierno federal y el Banco Mundial operaron un proyecto denominado "Generosidad" en 2002 con una duración de tres años desde el cual se impulsó el Modelo de Equidad de Género MEG: 2003. Su fin era certificar a instituciones públicas y del sector privado entre cuyos compromisos incluían promover la igualdad de oportunidades de hombres y mujeres en sus espacios de trabajo.

La aplicación del MEG - a cargo del Inmujeres- se definió como una política pública en 2006 y se entendió como un sistema de gestión con perspectiva de género. Se basaba en una estrategia que proporcionaba herramientas a las diferentes organizaciones para que asumieran el compromiso de revisar sus políticas y prácticas internas, y con ello reorganizar sus mecanismos a favor de la igualdad (Inmujeres, 2015).

El modelo (MEG) fue implementado por más de una década. Sus etapas eran 5: diagnóstico inicial, capacitación, asesoría, preauditoría y auditoría final. Cada una establecía sus requisitos, y las empresas que obtuvieran el distintivo MEG adquirían compromisos y beneficios supeditados al marco normativo de ese modelo. Los requisitos para adoptar el MEG consistían en 3: i) que la alta dirección de la organización solicitara adoptar el modelo dirigiendo un documento a la presidenta del Inmujeres; ii) que se enviara la cédula de registro; y iii) que le diera total cumplimiento al procedimiento establecido por el Inmujeres en cada etapa del proceso (Inmujeres, 2015). 
La cédula de registro o formatos en consideración requerían revisar las cláusulas relacionadas con diversos ejes que incluían analizar procedimientos, acciones asociadas con el reclutamiento y selección del personal, la capacitación, desarrollo profesional y compensaciones con igualdad de oportunidades; si la empresa promovía el balance entre la vida familiar y laboral; si se fomentaba un ambiente laboral y calidad de vida en la organización; si se generaban ambientes de salud en la organización; se buscaba la sensibilización y comunicación con enfoque de género; se prevenía y atendía el hostigamiento sexual; corregían los problemas de segregación ocupacional; entre otras, por lo que, una vez evaluada cada empresa, se le emitía un dictamen y recomendaciones procedentes.

La operación de ese modelo en México funcionó de 2003 a 2015 consiguiéndose la certificación de 220 organizaciones cuya vigencia del sello vencería el 31 de diciembre de 2015. Una vez que se concluía la vigencia por cada empresa, un siguiente paso consistía en someterse a una auditoría de seguimiento, por lo cual se podía volver a certificar al ampliarse la vigencia, en tanto atendiera las recomendaciones emitidas por la parte evaluadora. La integración y revisión de informes de corte cuantitativo permitían dar seguimiento al sistema de gestión de equidad de género, para con ello conseguir el reporte del nivel de aprobación del organismo certificador y se resolviera si procedía o no la (re)certificación conforme a la escala de evaluación.

La escala de evaluación consideraba tres grados: A, B y C. En el caso A, la decisión era aprobatoria. La puntuación considerada era 71 a 100 puntos. La evaluación B implicaba la aprobación condicionada con puntaje conseguido entre los 61 y 70 puntos (de 100). La evaluación $C$ era que la aprobación no procedía; la puntuación era 0 a 60 puntos (de un total de 100).

La indagación de las 220 organizaciones aprobadas por el MEG reportó que seis de ellas se ubicaban en el estado de Chihuahua: Agnico Eagle México, Auditoría Superior del Estado de Chihuahua, eCMMS, Rendilitros Gasolinera, Subsistema de Preparatoria Abierta del Estado de Chihuahua y la Universidad Autónoma de 
Ciudad Juárez (Inmujeres, 2015). Pero, al realizar un primer acercamiento en campo en 2016, atendido con la técnica bola de nieve, confirmó que dicho listado no estaba actualizado debido a que omitía el nombre de distintas empresas en Ciudad Juárez que contaban con esa distinción. Tal hallazgo tuvo que verificarse más adelante.

La acción de reflexionar que:

a) El nivel de aprobación del MEG de una organización dependía de una evaluación cuantitativa al final del proceso en una escala de 0 a 100; b) que había empresas certificadas en Juárez, Chihuahua, que no tendrían un seguimiento por la suspensión temporal del MEG; c) que la revisión de los informes de la efectividad del MEG presentados por diversas instituciones certificadas a nivel nacional sugerían que los ejes de Segregación Laboral por Razones de Género (SLRG) y Acoso Sexual (AS) figuraban - por lo general- en los últimos puestos de las tablas de resultados, sugiriendo que se buscaba minimizar la importancia de su contenido; y d) que los estudios con enfoque cualitativo sobre procesos de certificación de género en México fueran limitados llevó a cuestionarse lo siguiente: ¿Cuál era la factibilidad de indagar aspectos "observables" de lo que ocurría en torno a la segregación laboral por razones de género y dinámicas del acoso sexual en el siglo XXI al interior de una empresa certificada por el modelo de equidad de género ubicada en Juárez, Chihuahua?

El interés de explorar y profundizar en esos fenómenos, contemplando la oportunidad de conocer de propia voz la perspectiva de distintas personas en su ambiente laboral y considerando las exigencias del MEG, condujo a proponer los siguientes objetivos:

Explorar las experiencias de trabajadoras y trabajadores que laboraban en una empresa certificada en el Modelo de Equidad de Género ubicada en Juárez, Chihuahua, considerando dos ejes: el acoso/hostigamiento sexual (AS) y la segregación laboral por razones de género (SLRG).

Indagar las experiencias de AS de trabajadores(as) con base en tres categorías del MEG: conocimiento y percepción del tema, eventos de acoso, y atención y seguimiento a denuncias. 
Indagar las experiencias de SLRG de trabajadores(as) considerando tres categorías del MEG: discriminación, puestos y salarios, y relaciones entre compañeros(as).

\section{LAS PREGUNTAS DE INVESTIGACIÓN SON:}

¿Qué experiencias de acoso/hostigamiento sexual y segregación laboral por razones de género han enfrentado trabajadores y trabajadoras de una empresa certificada en el MEG ubicada en Juárez, Chihuahua?

¿Qué conocen y perciben del tema del acoso sexual, qué eventos de acoso sexual y qué atención o seguimiento a denuncias han experimentado trabajadores(as) de la empresa certificada en el MEG ubicada en Juárez Chihuahua seleccionada?

¿Qué vivencias de discriminación, puestos y salarios, relaciones entre compañeros(as) han experimentado trabajadores(as) de la empresa seleccionada y certificada en el $\mathrm{MEG}$, ubicada en Juárez, Chihuahua?

Por lo anterior, en concordancia con Rothery, Tutty y Grindell (1996) citado en Hernández, Fernández y Baptista (2010), se dispuso que esta investigación cualitativa requería ser conducida en los ambientes naturales de los participantes de forma que las variables no dieran cabida a ser controladas ni manipuladas disponiéndose como prioridad que los participantes determinarían los significados de los datos recogidos, por lo que estos últimos no se concentrarían en proporcionar valores numéricos.

Así sucede que ante la conveniencia, relevancia e implicaciones prácticas que advierte un estudio de esta naturaleza en términos académicos y metodológicos, se consideró viable disponer de las experiencias y puntos de vista del conjunto de individuos colaboradores dado que admitían generar teorías fundamentadas que condujeran, posiblemente, a establecer mecanismos y sugerir procedimientos o áreas de oportunidad para las organizaciones interesadas en adquirir la marca o sello "Igualdad Laboral y No Discriminación". 
Tal marca es promovida desde la Norma Mexicana NMX-R025-SCFI en igualdad laboral y no discriminación (NMX), cuya ejecución quedó a cargo de un consejo interinstitucional conformado por la Secretaría del Trabajo y Previsión Social (STPS), el Inmujeres y el Consejo Nacional para Prevenir la Discriminación (Conapred) (STPS, 2017); la cual, en 2020, es una propuesta que ha sustituido, en México, a la certificación del Modelo de Equidad de Género. O bien, complementa la propuesta del denominado "Sello de la igualdad de género" promovida desde el PNUD, según se expuso líneas arriba.

Para el cumplimiento de objetivos e indagar la búsqueda de respuestas a las interrogantes, este documento expone: la problematización y supuestos; el marco teórico y el diseño metodológico; presentación de resultados y comentarios finales a manera de conclusiones.

\section{PROBLEMATIZACIÓN Y SUPUESTOS DE LA INVESTIGACIÓN}

La problematización partió de reconocer que la cuantificación de un proceso de certificación puede ser trivial. Ello se corrobora cuando se encontró que la búsqueda de trabajos, informes e investigaciones que sirvieran como brújula orientadora para profundizar sobre el MEG en México eran limitados, que los reportes de empresas de seguimiento eran de corte cuantitativo y que los informes de las organizaciones estaban saturados de tablas y gráficas numéricas, subvalorando la riqueza de disponer de información de índole cualitativa.

La motivación de centrar la investigación en explorar las experiencias de participantes en torno al MEG sin medir, llevó a la revisión de literatura, encontrando los trabajos de Quintana (2011) y Macías y González (2013). Sus aportaciones fueron de gran valor al constituir una excepción en la manera de abordar el tema de la certificación. Partieron de conocer las experiencias de quienes colaboraron como parte del objeto de estudio, permitiendo tomarlas como un punto de partida para favorecer la recolección de datos, acordes con los objetivos de nuestro estudio. 
Con este aval, se decidió que las entrevistas semiestructuradas serían el camino adecuado para conocer sobre segregación laboral por razones de género y acoso sexual según las voces de las personas empleadas en la empresa seleccionada. En el caso de la conveniencia y accesibilidad a la empresa elegida, vale aclarar que, en efecto, tendría que verificarse si se apegaba a la política de equidad de género y a la igualdad de oportunidades del MEG, que señalan:

La empresa es responsable de "promover la igualdad de trato y de oportunidades en la búsqueda de eliminar las desigualdades por razón de género dentro de la organización, así como garantizar el acceso a obtener puestos y beneficios en igualdad de condiciones para hombres y mujeres" (MEG, 2015, pág. 43, apartado 4.1.2).

Es responsabilidad de la empresa asegurarse de que:

En la organización, hombres y mujeres sean tratados de forma equitativa, tengan las mismas oportunidades de acceso a ofertas de puestos y bonificaciones además de erradicar los estereotipos sexistas, culturales o intolerantes con las diferencias basadas en el género y/o sexo (MEG, 2015, pág. 62, apartado 4.3.4.2).

Ante este interés, la revisión de bases de datos del Inmujeres sugirió que Juárez, México, contaba con nueve empresas certificadas en el MEG en 2017 (Inmujeres, MEG, 2015: 71). De esa lista, se eligió una empresa maquiladora. La factibilidad de recolectar los datos en la empresa seleccionada requirió de lograr el acceso al ambiente como una condición necesaria para seguir con la investigación de modo que se corroborara si contaba con el sello de la certificación de género del Inmujeres.

Así ocurrió que se contactó a un gatekeeper (controlador del ingreso al ambiente o abre-puertas), a quien fue expuesto el proyecto, se desarrollaron relaciones, se conversó sobre cómo serían las rutinas de los participantes y se negoció cómo tendrían lugar 
tanto las entrevistas como el proceso de informantes que serían seleccionados.

Las primeras inmersiones en el ambiente permitieron realizar procesos de observación holística y se establecieron vínculos con posibles participantes para familiarizarlos con el planteamiento del problema. Como resultado de esta etapa, se consiguió formular un total de 6 supuestos, que señalaban:

- El hecho de que una empresa esté certificada en el MEG en México no garantiza que el acoso sexual o la segregación laboral no ocurra;

- Las mujeres son más acosadas sexualmente, más segregadas y mayormente discriminadas que los hombres;

- Los hombres no son acosados de la misma forma que las mujeres, o no sufren de acoso sexual con la misma frecuencia que ellas;

- Las mujeres tienen menor acceso a puestos de trabajo de mayor nivel y a menores salarios;

- Hombres y mujeres sufren acoso y les resulta difícil denunciar esos eventos; y,

- La voz de los varones tiene mayor peso y credibilidad en su ambiente laboral.

Otros resultados adicionales condujeron a determinar qué datos clave debían considerarse en la guía de las entrevistas, cuáles personas formarían parte de la muestra, cuándo y dónde sería conveniente citar a cada persona participante, preparar la elaboración de documentos o permisos, disponer de recursos y cuáles cronogramas procedían elaborar para comenzar con la recolección de datos. De igual manera, permitió identificar que entre los métodos disponibles para entender cómo perciben los participantes de la investigación sus experiencias, la fenomenología o la teoría fundamentada constituían una opción ideal, descartándose el estudio de caso, el interaccionismo simbólico, la hermenéutica, la etnografía, la historia de vida, la biografía y la historia temática en esta investigación. Mas, previo a presentar los datos recolectados 
y hallazgos obtenidos, se muestran a continuación algunas generalidades del marco teórico y del diseño metodológico.

\section{MARCO TEÓRICO Y DISEÑO METODOLÓGICO}

La revisión de investigaciones que permitieran definir el marco teórico y el marco metodológico para abordar el estudio de la segregación laboral por razones de género y el acoso/hostigamiento sexual en conjunción con la operación del Modelo de Equidad de Género sugirieron tomar el siguiente bosquejo, teórico y de autores, como guía:

La corriente teórica de posicionamiento se aborda desde el feminismo marxista (Giménez y Vogel, 2005).

El campo de estudio se aborda desde la Teoría de campos sociales de Bourdieu (1999).

El enfoque de la investigación es cualitativo tomando a Creswell (1998), Denzin y Lincoln (1994) como referencias.

La unidad de estudio fueron los colaboradores y colaboradoras de la investigación considerando la entrevista semi-estructurada para el acopio de información según la óptica de Grinnel y Unrau (2007).

El diseño de la investigación es fenomenológico conforme a Husserl (1945) y a Hernández, R. (2007). El procedimiento de análisis consideró la teoría fundamentada (grounded theory) ya que los hallazgos y la teoría emergieron con fundamento en los datos colectados (Denzen y Lincoln, 2000).

La muestra se determinó después de la inmersión inicial y no es probabilística (Hernández, Fernández y Baptista, 2010).

El muestreo fue cualitativo y las unidades de análisis se encontraron en el ambiente (Mertens, 2005). El número se determinó por la naturaleza del fenómeno y sus entendimientos. El tipo de muestreo fue por conveniencia con seis participantes de ambos sexos según la propuesta de Hernández, Fernández y Baptista (2010), Mertens (2005), Patton (2002) y Rizzo (2004). 
Los conceptos clave fueron segregación laboral y acoso sexual. Los principales exponentes tomados para el abordaje de estos debates fueron: Bourdieu (1998); Colin (2010); Kanter (1997); Anker (1997); Riquer (2010); Ferrer y Bosch (2006); Mackinnon (1987), Vandjik (1998); López y otros (2019) y un informe de la Comisión Nacional de Derechos Humanos, México (2017).

La aclaración de los ocho puntos previos propone, en resumen, lo siguiente. El feminismo marxista tiene sus bases en los planteamientos de Karl Marx y Federico Engels, por lo que se centra en ensalzar las relaciones desiguales de poder entre hombres y mujeres. La teoría marxista feminista argumenta que la opresión de la mujer se desenvuelve dentro del contexto capitalista, siendo el causante de la desigualdad económica, disparidad política y dependencia de la mujer al varón como proveedor y generador de ingresos, Giménez y Vogel (2005).

Añaden que la teoría del feminismo marxista expresa que la desigualdad en las relaciones sociales responde a una cuestión de clases (dominantes y subordinados), dentro de un contexto capitalista que se desarrolla en un sistema patriarcal. Es decir, las adecuaciones de los sistemas que rigen el mundo (económico, político, cultural, religioso, social) están configurados y establecidos bajo un pensamiento dominante y prevaleciente donde las mujeres son subordinadas a los hombres y, por ende, no corresponde con su naturalizada posición de inferioridad insertarse en espacios propios de hombres, por lo que al hacerlo se desplazan en estos bajo la consigna de conformarse con lo que se les otorga.

El balance de estas aportaciones conduce a cuestionar - por nuestra parte- si el sistema patriarcal es una propuesta obsoleta, si en efecto las mujeres son agentes subordinados e inferiores versus los hombres o si, en efecto, son desplazadas de ciertos ambientes por su condición de género.

Un texto más reciente, signado por Espasandín (2018), sugiere que las articulaciones entre marxismo y feminismo requieren contemplar las intersecciones de clase, raza, género y sexualidad desde las siguientes relaciones y dimensiones: clase y género, 
naturaleza y cultura, trabajo y amor, y entre producción y reproducción.

En suma, sus aportaciones sugieren cuestionar los siguientes aspectos: a) la lucha de clases no es capaz de explicar la opresión de la mujer desde la perspectiva estrictamente económica por lo que hay que contemplar el componente sexual; b) el análisis de la cultura "masculina" se opone a la cultura "femenina" por lo que la mujer debe ser liberada de su carga reproductiva (control de la fertilidad, reproducción artificial, partos, amamantamiento, cuidado de infantes) implicando la eliminación de los privilegios masculinos; c) se requiere entrecruzar jerarquías entre diversos hombres y mujeres de distinto color, jerarquía y clase para promover pactos y derechos, donde la variable "amor" es un instrumento cultural del poder masculino para mantener a las mujeres en una condición de ignorancia donde amor y trabajo son prácticas humanas que se reservan para relaciones amorosas heterosexuales no igualitarias.

En esta revisión postula, además, que el poder de los hombres requiere ser explicado y no la opresión o subordinación de las mujeres; que las condiciones de la reproducción y sus efectos en la producción demandan observar cómo el tiempo ha permitido combinar trabajo remunerado y no remunerado para las mujeres facilitando el acceso a puestos de jerarquía o si los efectos han fortalecido la presencia de mujeres y hombres en el trabajo o en el hogar.

En cuanto a Bourdieu (1999), la teoría de campos sociales contempla que tales campos son espacios de juego históricamente constituidos con instituciones específicas y leyes de funcionamiento propias. Un campo es una configuración de clases o relaciones sociales que son necesarias para su existencia y donde dichas relaciones tienen una razón de ser y un estatus social que hace interactuar a los individuos de tal o cual manera.

El ámbito laboral como objeto de estudio en esta investigación se sitúa en el campo de la cultura, pues es donde las relaciones e interacciones entre individuos son indispensables para el funcionamiento del sistema donde se desenvuelven. 
Denzin y Lincoln (1994) refieren que la investigación cualitativa es multimetódica, naturalista e interpretativa, y señalan que en esta se indagan situaciones naturales intentando dar sentido o interpretar los fenómenos en los términos del significado que las personas les otorgan. Creswell (1998), en cambio, hace énfasis en que la investigación cualitativa puede transformar al mundo en problemas sociales y humanos, en darles voz a los y las participantes en su complejidad para describir y para interpretar. Los autores coinciden en que la investigación cualitativa permite participar en el problema, vivirlo de cerca, observar dónde se da su naturaleza y tener una interacción cara a cara porque quien investiga se considera como una herramienta para la recolección de datos.

Por la naturaleza de este estudio, se utilizó un diseño fenomenológico; cabe entenderlo como "El estudio de los fenómenos [...], el mundo es aquello que se percibe a través de la conciencia del individuo y se propone interpretarlo según sus experiencias (Husserl, 1945: 21). Por su parte, Hernández, Fernández y Baptista (2010) explican que primero se debe identificar el fenómeno y luego recopilar los datos de las personas que lo han experimentado, para finalmente desarrollar una descripción compartida de la esencia de las experiencias para todos los participantes, lo que vivenciaron y de qué forma lo hicieron.

En suma, el estudio fenomenológico es la explicación de las vivencias de cada participante basadas en experiencias concretas a fin de obtener una comprensión teórica que permita entender y lidiar con el fenómeno de estudio.

En cuanto a la muestra, es de carácter cualitativo; no se fijó a priori ni se buscó generalizar resultados a una población más amplia. Se identificó el ambiente propicio, los grupos potenciales de participación y finalmente los individuos. La muestra fue guiada según los propósitos de la investigación y bajo el interés de disponer de información para comprender el problema de estudio, según Hernández, Fernández y Baptista (2010) y Mertens (2005). En palabras de Patton (2002), una ventaja del muestreo cualitativo reside en lograr que los casos elegidos proporcionen la mayor 
riqueza de información posible para estudiar sustancialmente la pregunta de investigación y responderla. Esta fuerza se confirmaría al revisar, sistematizar y analizar los datos recogidos.

Los casos seleccionados (léase personas) se sujetaron a cumplir con criterios de rigor, estratégicos y éticos dado que se formalizó el consentimiento informado de los datos recogidos, los participantes se sujetaron a responder las preguntas de la entrevista y su reclutamiento fue abierto hasta lograr la saturación de las categorías (Hernández, Fernández y Baptista, 2010). La muestra fue por conveniencia, al igual que Rizzo (2004), ya que fueron los casos disponibles a los cuales se tuvo acceso.

Las entrevistas semiestructuradas utilizadas en esta investigación fueron el instrumento para el acopio de información. Según Grinnel y Unrau (2007) este tipo de entrevista se basa en una guía de asuntos o preguntas con la libertad de introducir algunas adicionales para precisar conceptos o ampliar la información. Esta técnica permitió que las y los trabajadores relataran sus experiencias y percepciones del Modelo de Equidad de Género en relación con las categorías de segregación laboral por razones de género y el acoso sexual.

El formato de entrevistas semiestructuradas facilitó la creación del guión de preguntas divididas en dos secciones: la primera con preguntas enfocadas a la segregación laboral por razones de género y la segunda con preguntas sobre el acoso sexual (Figura 1). Entre los tipos de preguntas, según Mertens (2005) se incluyeron: de opinión, de expresión de sentimientos, de conocimientos y de antecedentes.

Una vez obtenidos los datos, se transcribieron, codificaron, describieron e identificaron similitudes y diferencias en los testimonios. Ello permitió relacionar fragmentos con los conceptos clave del estudio.

De los conceptos clave se procedió a sintetizar lo siguiente: el concepto de segregación laboral hace referencia a la división sexual del trabajo que según Bourdieu (1998) son estructuras que permanecen en el imaginario colectivo a partir de aplicar tres principios: 1) Las funciones consideradas adecuadas para las mu- 


\section{Figura 1. Formato de entrevista semiestructurada.}

Antes de comenzar quiero agradecer su disposición para compartir información de su vida profesional y comentarle que toda la información que se trate en estos encuentros está protegida por el código de ética de la UACJ. Además, su uso será estrictamente con fines académicos y bajo un esquema de confidencialidad. Como le comenté en nuestro primer acercamiento, le reitero que puede realizar cualquier pregunta en el momento que estime pertinente, y cuenta con la facultad de ejercer su derecho a detener la entrevista cuando lo desee.

\begin{tabular}{|l|l|}
\hline Primera sección & Segunda sección \\
\hline $\begin{array}{l}\text { Tema: Segregación por razones de gé- } \\
\text { nero }\end{array}$ & Tema: Acoso y hostigamiento sexual \\
\hline
\end{tabular}

- Al solicitar trabajar en la empresa ¿Consideró que tendría algún tipo de problemática por (no) ser mujer?

- ¿Cómo se le informó sobre el tema del acoso y hostigamiento sexual en este (su) trabajo?

- ¿Hubo alguna ocasión en la que (no) • ¿Recibió pláticas o talleres sobre el tema? ser mujer influyera en conseguir un • ¿Cómo se da seguimiento a una situación puesto de trabajo?

- Al entrar a laborar en esta empresa que cuenta con la certificación de género, ¿Se le informó sobre este tema y cómo tendría que laborar bajo este enfoque?

de acoso u hostigamiento sexual desde la certificación?

- Como mujer (hombre), ¿Siente que está en mayor riesgo de sufrir acoso u hostigamiento?

- En la certificación se plantea que debe existir un trato equitativo para mujeres y hombres que laboran en esta empresa ¿Ha sentido que el trato que recibe por parte sus compañeros varones (as/mujeres) es diferente?

- ¿Cómo es el trato entre mujeres (hombres) en esta empresa?

- Hablemos del salario. ¿Le parece que es el monto adecuado para usted?

- ¿Ha sentido alguna vez que su salario o prestaciones están condicionados por ser mujer (hombre) en comparación con el de sus compañeros en puestos semejantes?

- La certificación establece que haya igualdad de oportunidades entre hombres y mujeres ¿Considera que esto se cumple en esta empresa?

- ¿Considera que las políticas de prevención de la certificación son suficientes para prevenir y evitar el acoso y el hostigamiento en esta empresa?

- ¿Se siente protegido(a) y seguro(a) dentro de su espacio laboral toda vez que la empresa está certificada?

- ¿Usted ha pasado por alguna situación de acoso u hostigamiento sexual en este trabajo? Si es así ¿Puede contarme qué ocurrió o cómo ocurrió? Si no es así, ¿Conoció o conoce algún caso ocurrido de acoso y hostigamiento sexual en esta empresa?

- ¿Qué hizo usted para hacer frente a esa situación?

- ¿Cómo se resolvió esa situación?

- ¿Considera que fue la forma adecuada para resolver esa situación?

- ¿Sabe o conoce si la persona acosadora fue sancionada o si está bajo vigilancia? ¿Sabe qué ocurrió con tal persona?

- En su experiencia, ¿Le ofrecen oportunidades o prestaciones antes que a sus compañeros varones?

- ¿Siente que es tomada(o) en cuenta y que su opinión se considera igual de importante que la de sus compañeros varones (compañeras mujeres)?

- ¿Cómo siente que se percibe a la persona acosada? ¿Cómo la ven el resto de sus compañeros(as) si se dan cuenta de una situación así?

- Según lo que usted sabe ¿Cómo es el trato o la intervención por parte de quienes deben dar atención a este tipo de situaciones en la empresa?

Fuente: Elaboración propia. 
jeres (actividades domésticas, enseñanza, cuidado, servicio); 2) Se sostiene que una mujer no puede tener autoridad sobre un hombre, por lo que en determinadas circunstancias se ve postergada por un hombre en posición de autoridad y relegada a posiciones/ puestos de servicio o asistencia; 3) El hombre siempre ha tenido y sigue teniendo el monopolio del conocimiento y manipulación de la tecnología por lo que se asocia que ciertos trabajos son considerados "para hombres" y por ende una mujer no es "capaz" de realizarlos.

López y otros (2019) plantean que la literatura sobre segregación distingue dos tipos: a) la segregación horizontal u ocupacional donde la tendencia es que hombres y mujeres desempeñen profesiones distintas, y b) la segregación vertical o jerárquica, que alude al reparto desigual de puestos directivos (desempeñados en su mayoría por varones) limitando el desarrollo profesional de las mujeres y que alcancen puestos mejor remunerados. Advierten que la composición heterogénea de los puestos de trabajo por razón de género pueden vincularse con la brecha salarial entre hombres y mujeres o con la presencia de obstáculos que pueden perjudicar a las mujeres y no necesariamente con situaciones discriminatorias.

Colin (2010) escribió también que la segregación se manifiesta de forma horizontal y vertical. Explica que la primera forma corresponde a aquella en la que se observa una concentración de mujeres que se emplean en una serie de sectores, categorías y profesiones determinadas que son consideradas "femeninas" y los hombres, por su parte, se encuentran en aquellas consideradas "masculinas". La segregación vertical se define como la dificultad que encuentran las mujeres para acceder a puestos de responsabilidad o de mayor escala jerárquica en las organizaciones, donde existe una barrera invisible que dificulta el acceso de las mujeres a posiciones de poder y de toma de decisiones en el marco laboral.

Kanter (1997) considera que las dificultades laborales de género son producidas por la posición de dominio-sumisión que se desarrolla en las organizaciones, pues la idea de que las mujeres son subordinadas a los hombres predomina en este y otros espacios; 
por lo que las mujeres son consideradas "adecuadas" para ocupar aquellos puestos que estén por debajo de la jerarquía masculina.

Anker (1997) puntualizó que la segregación basada en el sexo está muy extendida ya que se gesta y se reproduce por todo el mundo, así sea incluso en aquellos lugares con alto desarrollo económico, sistemas políticos, entornos religiosos, sociales y culturales; la segregación laboral es un evento que persiste en todos los mercados de trabajo a nivel global.

La segregación de las ocupaciones entre los sexos "perjudica a las mujeres directamente, porque tiene efectos muy negativos sobre como las ven los hombres y como se ven a sí mismas" (Anker, 1997: 343).

De lo anterior se infiere que la persistencia de los estereotipos socio-sexuales genera consecuencias nocivas no solo en la reproducción de los estereotipos basados en lo que socialmente se considera aceptable para femenino y masculino, sino que también son dañinos en el ámbito de la formación y desarrollo profesional pues se perpetúan las desigualdades entre hombres y mujeres de una generación a otra. En suma, los ambientes laborales pueden resultar contraproducentes en tanto eviten políticas y estrategias a favor de la igualdad y la equidad.

De la noción de acoso sexual se observó que es un término que emergió del feminismo de los años setenta del siglo XX como fruto de la reflexión de algunas feministas norteamericanas y británicas, quienes hablaron desde sus experiencias tanto en el mundo laboral como en el escolar. Las feministas estadounidenses acuñaron el término "sexual harassment", y denunciaron la existencia de chantajes sexuales en la esfera laboral que en ese entonces eran considerados parte de la conducta "normal" masculina.

Al respecto, Ferrer y Bosch (2006) señalaron que las feministas lograron el establecimiento de la primera legislación contra el acoso sexual en el trabajo, consiguiendo influir en otros países hasta extenderse por varias partes del mundo. El acoso sexual se define como una conducta intrusiva o indeseada de los hombres en la vida de las mujeres. En concreto, se dijo que, "más que como un fenómeno ligado a la dominación sexual, [el acoso sexual] son un 
conjunto de prácticas y actitudes que infantilizaban a las mujeres en el trabajo, obstaculizaban su integración o negaban su valor como profesionales" (Riquer, 2010: 63).

La base de esta concepción es que el acoso sexual pone de manifiesto una relación de poder y se encuentra íntimamente ligado con la situación de desventaja y de inferioridad de las mujeres en la esfera laboral. Esta expresión sugiere que un objetivo práctico del acoso es intimidar y subordinar a toda mujer que ha decidido dejar el espacio al que se le confinó (casa/lo privado) buscando insertarse en el mercado laboral (lo público).

Otra definición del acoso sexual señala que es toda imposición indeseada de requerimientos sexuales en el contexto de una relación de poder desigual, que tiene lugar principalmente porque las mujeres ocupan posiciones y funciones laborales inferiores. Esto es:

"El acoso sexual [...] es un fenómeno que afecta a un grupo definido por el sexo de las personas que lo componen: las mujeres, para tratarlas de una manera especial que tiene repercusiones deplorables y ataca su condición de trabajadoras. El acoso sexual impone restricciones a las mujeres que no se aplican a los hombres. Las priva de posibilidades que pueden beneficiar a los empleados masculinos sin condicionantes sexuales." (Mackinnon, 1987: 23).

Esta revisión permitió observar que los discursos feministas ponen de manifiesto que el acoso sexual es un mecanismo de control para mantener una relación de dominación-subordinación que convierte a la mujer en un objeto del que se puede disponer a conveniencia. Dicho mecanismo se asienta sobre creencias populares de la organización social que se legitiman a través de la institucionalización y socialización de normas y sistemas, creencias o "ideologías" en las que, según Vandjik (1998), se reproducen y validan en las sociedades que las practican y que se actualizan día a día volviéndose un ejercicio cotidiano tolerado y normalizado, dando como resultado que en el caso de muchas mujeres que sufren acoso no puedan identificarlo como una agresión. 
Por su parte, la CNDH (2018) de México, plantea que el acoso sexual es "cualquier comportamiento (físico o verbal) de naturaleza sexual que tenga el propósito o produzca el efecto de atentar contra la dignidad de una persona; en particular, cuando se crea un entorno laboral intimidatorio, degradante u ofensivo" cuyas manifestaciones obedecen a dos situaciones: 1) el chantaje sexual o quid pro quo (algo a cambio de algo) que puede ser explícito o implícito; y 2) el ambiente laboral hostil. Aclara que en una situación de acoso sexual participan dos: la víctima (mujer u hombre) y el acosador (la persona que violenta o acosa en el ámbito laboral).

Puntualiza, también la CNDH (2018), que "el hostigamiento sexual es el ejercicio del poder, en una relación de subordinación real de la víctima frente al agresor en los ámbitos laboral y/o escolar. Se expresa en conductas verbales, físicas o ambas, relacionadas con la sexualidad de connotación lasciva”. Por ello, en México se dispone del Protocolo para la Prevención, Atención y Sanción del Hostigamiento Sexual y Acoso Sexual donde ambos actos se consideran una forma de violencia donde opera un ejercicio abusivo de poder que coloca a la víctima en un estado de riesgo o indefensión que se concreta en uno o varios eventos, aun cuando no haya subordinación de la víctima.

Y se aclara que, en cuanto a las acciones de acoso sexual u hostigamiento, pueden ser de tipo físico, verbal o no verbal; por lo que los daños en las víctimas pueden ser de carácter físico y psíquico o social; que al final suponen costos que afectan los derechos humanos, a los empleadores y a la sociedad.

En esta lógica, procede confirmar si son únicamente las mujeres quienes son acosadas o si ocurre que los hombres también son víctimas de acoso en su ambiente laboral. Para confirmar qué ocurre en términos de segregación laboral y acoso en la esfera laboral, se presentan a continuación los resultados obtenidos en el trabajo de campo. 


\section{RESULTADOS OBTENIDOS}

A manera de recordatorio, el interés de esta investigación se centró en recuperar las experiencias de las y los trabajadores que laboraban en una empresa certificada con el Modelo de Equidad de Género (MEG), sobre segregación laboral por razones de género (SLRG) y acoso/hostigamiento sexual (AS) en el periodo del levantamiento de información. La información disponible y validada permitió realizar un análisis de los datos recolectados desde la propuesta de la teoría fundamentada incluyendo elementos del diseño fenomenológico.

Las seis personas de la muestra con nombres ficticios, entrevistadas, fueron: Antonio, Cristina, Héctor, Enriqueta, César y Mila. Su selección consideró tres criterios. Primero, trabajaban en la empresa maquiladora seleccionada; la empresa contaba con la certificación en el Modelo de Equidad de Género. Se anticipó que cada participante estuviera familiarizado(a) con el MEG. En segundo lugar, se consideró y confirmó su puesto de trabajo y nivel jerárquico (similares). Por último, se tuvo noción que las personas experimentaron ya sea alguna situación de segregación o de acoso en la empresa. Se efectuaron al menos dos sesiones de entrevista con cada persona. Los encuentros fueron durante mayo y junio de 2017. Los datos generales de cada participante sugirieron lo siguiente (Figura 2).

En pocas palabras, se puede ver que las personas entrevistadas en campo fueron tres mujeres, tres hombres, cuyo rango de edad comprendía de los 26 a los 45 años cumplidos. La antigüedad laboral del grupo difiere al comprender de 2 a 15 años productivos. Dos personas eran casadas, dos solteras y dos estaban comprometidas. Dos tenían hijos y cuatro declararon no ser madre o padre de familia. Todas tenían el grado de ingeniero(a). A continuación, se exponen algunos hallazgos, primero de la SLRG y posteriormente del AS, considerando algunos testimonios (o parte de ellos) de las y los participantes, destacando ciertos planteamientos teóricos y dando cabida a algunas preguntas surgidas a través del análisis de las experiencias. 
Figura 2. Datos generales de participantes de la muestra

Antonio: hombre, 28 años, 6 años de antigüedad laboral, ingeniero de calibración, casado, padre de dos hijas pequeñas.

Cristina: mujer, 28 años, 3 años de antigüedad laboral, ingeniera de calibración, titular de un proyecto propio, soltera con pareja, sin hijos(as).

Héctor: hombre, 34 años, 11 años de antigüedad laboral, ingeniero de calibración con especialidad en mantenimiento de máquinas, comprometido para casarse, sin hijos.

Enriqueta: mujer, 45 años, 15 años de antigüedad laboral, ingeniera, supervisora del departamento de calibración, casada, madre de dos hijos.

César: hombre, 30 años, 5 años de antigüedad laboral, ingeniero de calibración, soltero, sin hijos.

Mila: mujer, 26 años, 2 años de antigüedad laboral, ingeniera de calibración, comprometida para casarse, sin hijos.

Fuente: Elaboración propia.

\section{HALLAZGOS DE LA SEGREGACIÓN LABORAL POR RAZONES DE GÉNERO (SLRG)}

El estudio de la SLRG se desagrega en tres categorías: discriminación, puestos y salarios, y relaciones personales. En el primer caso, referido a los obstáculos que se les presentaron durante su proceso de contratación, o si consideraron que se les discriminaba de alguna forma por su sexo para ser contratados(as), se obtuvieron respuestas como las siguientes.

\section{Categoría 1: Discriminación}

Antonio: En realidad, no, sí te hacen una serie de preguntas que tienen que ver con el trato, con las relaciones humanas. Pero la verdad es que fue algo sencillo, fue rápido el proceso de contratación. (Entrevista personal, 9 de mayo de 2017). 
Héctor: No, ninguno. Pues fue un proceso sencillo realmente en el puesto que yo solicitaba pues no era, no era muy competido (Entrevista personal, 11 de mayo del 2017).

Enriqueta: Sí. Fíjate que había mucha competencia, principalmente por hombres y cuando yo metí mi aplicación para ingeniera pues me lo negaron porque no tenía el título aún. Yo me embaracé, y pues tuve que posponer la carrera, y cuando retomé todo, pues, presenté mi constancia de que había terminado la ingeniería, pero siempre me sacaban el título por delante. Yo no sé si a todos les pasó igual, pero no creo (ríe). A mí me dieron un puesto administrativo, fui por algún tiempo asistente de gerencia con la promesa de que, cuando tuviera el título pues, me iban a subir a ingeniería; pero esto si se tardó más de lo que hubiera querido porque, pues mi sueldo no era la gran cosa, así que, [...] me tuve que esperar (Entrevista personal, 14 de mayo 2017).

Mila: A mí al principio como que sentí que no me tomaron muy en serio por mi edad y porque pues me veo aún más joven de lo que soy (ríe). [...] cuando postulé, pues tenía recién 24, y aunque trabajé en otra fábrica antes, pues no tenía, así como que toda la experiencia del mundo tampoco. Siento que... (hace una pausa), siento que, a lo mejor por eso de la experiencia, pero quién sabe. Es que me dijeron que me hablaban por teléfono o me mandaban un mail si se hacía la contratación, pero se me hizo medio raro porque había otros muchachos ahí y salieron contratados. A mí me hablaron dos semanas después [...] Me dieron el puesto, pero estaba en lo que le dicen el periodo de prueba [...] (ríe) (Entrevista personal, 3 de junio del 2017).

En cuanto a las dinámicas laborales que deben seguirse según la certificación del MEG, en relación con la manera en que empleados y empleadas deben interactuar entre sí, se informó:

Antonio: Yo me he esforzado por llevar a cabo al pie de la letra esto. No le doy preferencia a ninguna de las personas que tengo a mi cargo ni hablo mejor de unos que de otros; procuro ser lo más imparcial 
posible. Desgraciadamente, pues hay como cosas que se van perdiendo, costumbres o ciertos reglamentos que empiezan a hacerse a lado poco a poco [...] otros compañeros con el mismo cargo o incluso en cargos más elevados, empiezan a tener ciertas preferencias de un género sobre otro (Entrevista personal, 9 de mayo de 2017).

César: Fíjate que no me acuerdo con exactitud cada cosa que nos dijeron de esto porque ya pasó alguito de tiempo (ríe), [...] bueno tenemos todos que tener presente, es que la manera de llevarnos entre nosotros no debe dar pie a que alguien, sea mujer o sea hombre, sienta que está siendo discriminado por ello, ¿me explico? O sea, siempre han sido muy puntuales y no solo por la certificación sino por otros reglamentos de la empresa, a que prácticamente ni se nos ocurra hacer o decir algo que sea discriminatorio y pues este, principalmente con las mujeres porque aparte es visto como un delito, sobre todo si están embarazadas [...] o [...] como cuando alguien se sabe que es homosexual pues, tampoco debe tratársele mal o cuando hay alguien con alguna discapacidad. [...] tenemos que ser muy respetuosos (Entrevista personal, 15 de mayo de 2017).

Cristina: Pues cuando yo entré a la empresa, ésta ya estaba certificada. De hecho, esto te lo informan en un taller o plática que forma parte de la capacitación que se te da para entrar a la empresa y ahí en esa charla, yo recuerdo que se nos dijo que teníamos que trabajar en el respeto entre compañeros, pues entre hombres y mujeres y todo esto nos dijeron que porque la empresa trabaja bajo el enfoque de la igualdad y de la equidad y de la paridad; [...] ahora que recuerdo, de vez en cuando dan estos papelitos, estos como volantes donde dice así cosas como cero tolerancia a la discriminación, o que discriminar a las mujeres por esto o por aquello es un delito (Entrevista personal, 15 de mayo de 2017).

Enriqueta: Pues fue algo así como un taller, una capacitación donde se nos dijo que la dinámica de trabajo a partir de esto de estar certificados, pues iba a ser muy diferente. Teníamos que cuidar mucho esto de la discriminación, tenía que haber igualdad entre hombres 
y mujeres. A grandes rasgos pues, se nos dijo sobre la importancia de esto, sobre todo como que se le comenzó a dar más atención al trato que recibian, bueno recibiamos las mujeres porque pues por ejemplo a veces sí había tratos muy discriminatorios [...] (Entrevista personal, 14 de mayo de 2017).

\section{Categoría 2: Puestos y salarios}

Entre las indagatorias de esta categoría se tornó pertinente conocer las percepciones sobre si el salario o pago le resultaba adecuado a cada persona entrevistada. Enunciaron testimonios como los siguientes.

Antonio: Yo creo que mi salario es justo, creo que me pagan bien por lo que hago (Entrevista personal, 9 de mayo de 2017).

Héctor: Mi salario... (hace una pausa). No es adecuado, pero es... yo siento que es más una cuestión política que... bueno el salario no es adecuado en ningún lado (Entrevista personal, 11 de mayo de 2017).

César: (Ríe) ¿Por qué hablamos de cosas tristes? Es que esto del salario no creo que se pueda definir como justo, más bien hay que "aguantarse" con lo que marca la ley y pues la ley está muy mal (ríe). Pero ya hablando en serio, pues me pagan relativamente bien por lo que hago, o sea, en comparación con los operadores o de otros trabajos que sé que son muy mal pagados, pues yo estoy "bien" (hace ademán de comillas) (Entrevista personal, 15 de mayo de 2017).

Cristina: Yo considero que mi salario está bien y a la vez no. Sí, porque pues creo por mis labores y lo que me desempeño, considero que me pagan bien, pero tú sabes, uno siempre quiere más como en todos lados [...] tienes que ir escalando si quieres ganar más, tienes que ir subiendo peldaños, así que pues por ahora yo considero que estoy bien (Entrevista personal, 15 de mayo de 2017). 
Enriqueta: ¿Qué si me parece adecuado mi salario? No. ¿Por qué? Por ser mujer. Mire, desde mi punto de vista, yo soy ama de casa, tengo hijos, tengo una casa que atender fuera del trabajo y cuando se me pide quedarme extra no puedo, se me requiere para andar en alguna actividad extra de la empresa, yo no puedo. ¿Entonces eso qué pasa? Repercute, baja mi salario, [...] En cambio [...] la mayoría de los que son hombres pues sí tienen más tiempo de ir a todo y de quedarse más tiempo extra, por eso ganan más que yo (Entrevista personal, 14 de mayo de 2017).

Mila: Uy, ya empezamos mal (risas). Mira, yo empecé ganando bien poquito porque, como te comenté al principio, me pusieron a prueba para ver si daba el ancho, y la verdad era una miseria lo que me pagaban [...] No creo que mi salario esté del todo mal ahora, pero tampoco es lo que una desearía (Entrevista personal, 3 de junio de 2017).

Un segundo aspecto de la categoría "puestos y salarios" llevó a cada participante a relatar cuál era su percepción y experiencia respecto a las diferencias salariales que existían entre mujeres y hombres a pesar de laborar en los mismos puestos de trabajo. Expusieron lo siguiente.

Héctor: Desconozco si se lleva a cabo en esta empresa esto del 50/50 de tener hombres y mujeres en todos los puestos [...] en la capacitación que nos dieron mencionaron esos temas, mencionaron que por lo regular el salario de una mujer era mínimo o era, no sé, menor que el hombre entonces, por eso empezaron a meter este tipo de capacitaciones de género y a implementar la equidad y esas cuestiones"(Entrevista personal, 11 de mayo de 2017).

Enriqueta: Sí licenciada, reitero nuevamente [...] mi salario sí se ve o es menor que quienes sí pueden aprovechar estas oportunidades, como en el caso de los ingenieros. Aunque estemos en la misma área ellos pueden y ganan más por esto que le comento (Entrevista personal, 14 de mayo de 2017). 
En cuanto a la tercera categoría de la segregación laboral por razones de género, se abordaron aspectos sobre la importancia dada a las opiniones y toma de decisiones con ambos sexos y la atención brindada a las diferencias basadas en el sexo. Ello implicó conversar del trato entre unos y otras. Se plantean algunas respuestas.

Categoría 3: Relaciones entre compañeras y compañeros

Héctor: Pienso que la posición jerárquica que ocupan en el personal administrativo, los ingenieros y quienes tengan puestos por decirles de alguna manera superiores, regularmente sí es más tomada la opinión de los varones puesto que hay más varones en el área administrativa que mujeres por cuestión de mayoría, simple nada más. Si hay mujeres en puestos de mando, de autoridad, pero siempre hay un equipo o alguien arriba de ellas y por lo general son hombres ¿no? [...] a veces te puedes dar cuenta que una mujer toma una decisión, pero ciertamente no fue ella sola quien la tomó o estaba manipulada por alguien más, esto ocurre con mucha frecuencia (Entrevista personal, 11 de mayo de 2017).

César: A mi muchas veces me han dado el avión por ser como soy (ríe). Sí está todo esto de que el trabajo en equipo, de que nadie es superior a nadie y bla, bla, bla, pero la verdad es que esto que preguntas como que, si nuestras opiniones cuentan, mira finalmente quienes llevan el barco son los que deciden [...] aunque haya buenas ideas y vengan de hombres o mujeres, al final, a veces nada más disfrazan que te hacen caso, pero terminan haciendo lo que les parece mejor [...] hay que hacer lo que dicen los superiores [...] pero sí lo he pasado mal algunas veces [...] porque, aunque sea hombre, sí me ha tocado que me tratan diferente por ser gay (Entrevista personal, 15 de mayo de 2017).

Cristina: Yo siento que sí he tenido buenas experiencias laborando con mis compañeros hombres. La mayoría de ellos son muy capaces e incluso he tenido que reconocer que muchos de ellos tienen 
mejores ideas y mejores habilidades y capacidades que yo, pero te confieso que esto me ha ayudado a mejorar mi trabajo para crecer incluso como persona. Nunca he sentido que se me ignore por completo [...] aunque sí se me ha cuestionado en algunas cosas, que se haya invalidado por completo mi palabra, jamás (Entrevista personal, 15 de mayo de 2017).

Mila: Yo creo que en esto de las opiniones y las decisiones a veces le dan más importancia a lo que dicen quienes tienen como más experiencia. A mí sí, directamente me han dicho que no a algunas de mis sugerencias o me las cambian de mi idea original con lo que dice algún otro compañero que según tiene más experiencia [...] pero pues también a veces sí aceptan mis ideas, pero pues hay que seguir un proceso como de revisión para ver si es adecuada la propuesta o lo que sea (Entrevista personal, 3 de junio de 2017).

En conclusión, la figura 3, resume en qué concordaron y discordaron las personas entrevistadas en materia de discriminación, puestos y salarios, así como en el aspecto de relaciones entre el personal.

Algunas lecturas que pueden exponerse al respecto son: al parecer, la empresa presta atención para evitar la concentración de mujeres u hombres en determinadas ocupaciones, por lo que se presume un reparto "equivalente". Sin embargo, las personas entrevistadas ponen de manifiesto que sí han percibido obstáculos en materia de promoción que pueden reconocerse como acciones discriminatorias, impidiéndoles el desarrollo profesional evidenciando el no acceso a igualdad de oportunidades. De esta manera, la presencia de segregación ocupacional puede advertirse en la presencia de brechas salariales donde las mujeres, dados sus compromisos familiares y personales, se ven obligadas a rechazar ofertas que incrementarían sus remuneraciones salariales.

En el caso de las diferencias o semejanzas en el grupo entrevistado, se aprecia que tanto hombres como mujeres han invertido en su formación, en su experiencia laboral obteniendo como un resultado oportunidades laborales. No obstante, tanto unos como 
otras sí han enfrentado trayectorias diferentes en esa dinámica. Las mujeres reconocen que las tareas domésticas y el cuidado de sus dependientes son "variables" (vinculadas con el amor, según el feminismo marxista) que deben valorar en su ejercicio laboral asumiendo los costos derivados. En el caso de los varones, pareciera que disponen de mayor flexibilidad y menores riesgos para optar por mejores remuneraciones en tanto resuelven de manera relativamente más sencilla y rápida la conciliación entre la vida familiar y la vida laboral. Sin embargo, ello no significa que están exentos de hacer frente a prejuicios, cargas sociales y culturales que les conduzcan a tomar decisiones "voluntarias". Por ello, cabe aceptar que existen factores distintos a los económicos que determinan las posiciones de desventaja de hombres y mujeres en el ámbito laboral.

En consecuencia, queda pendiente proponer una agenda de género que cuestione seriamente lo "socialmente aceptable" en términos de segregación laboral por razones de género de forma que impere el respeto a la dignidad, se cumplan los derechos civiles y humanos al que cada hombre y mujer debe acceder, especialmente en su ámbito laboral. Al parecer, la discriminación tiene diversas expresiones, de más sutiles a más evidentes, lo que requiere atención. En el caso de los puestos y salarios, su definición depende de diversos factores. Y por lo que se refiere a las relaciones personales, la certificación de género sí ha contribuido a que el personal atienda las reglas dictadas por la empresa, aunque las medidas han sido no suficientes. 
Figura 3. Segregación Laboral por Razones de Género (SLRG): Concordancias y discordancias en testimonios según categoría.

\begin{tabular}{|c|c|}
\hline Categoría & Concordancias \\
\hline Discriminación & $\begin{array}{l}\text { La discriminación obedece a un problema de género en donde } \\
\text { las mujeres son más discriminadas que los hombres debido a } \\
\text { las ideas y estereotipos sociales en las que ellos son mejores } \\
\text { para desempeñar ciertos puestos de trabajo que ellas. }\end{array}$ \\
\hline $\begin{array}{c}\text { Puestos } \\
\mathrm{y} \\
\text { salarios }\end{array}$ & $\begin{array}{l}\text { Todos y todas tienen acceso a puestos y salarios de igual forma } \\
\text { debido a que la certificación así lo estipula. } \\
\text { Las mujeres disponen de menos tiempo que los hombres para } \\
\text { trabajar horas extras que les generen mayores ingresos. } \\
\text { Los hombres tienen más tiempo para atender actividades extras } \\
\text { que les reportan beneficios salariales debido a que se asume } \\
\text { que no son ellos quienes deben atender el hogar o a los hijos. }\end{array}$ \\
\hline $\begin{array}{c}\text { Relaciones } \\
\text { entre } \\
\text { personal }\end{array}$ & $\begin{array}{l}\text { Están basadas en el respeto mutuo. } \\
\text { Son mayormente buenas debido a los valores que se promueven } \\
\text { en la certificación. } \\
\text { El trato que reciben hombres y mujeres es diferente basados } \\
\text { en la manera de hablarse, los acercamientos físicos e incluso la } \\
\text { orientación sexual. }\end{array}$ \\
\hline Categoría & Discordancias / sugerencias del tema \\
\hline Discriminación & $\begin{array}{l}\text { Que el proceso de contratación haya sido igual para hombres y } \\
\text { mujeres lo que no es algo fácil y rápido. Para ellas, se observa } \\
\text { que hicieron frente a algunas problemáticas para ser finalmente } \\
\text { contratadas. } \\
\text { Que la discriminación sea un tema al que se le dé relativa baja } \\
\text { importancia sugiere que requiere más atención. }\end{array}$ \\
\hline $\begin{array}{l}\text { Puestos } \\
\mathrm{y} \\
\text { salarios }\end{array}$ & $\begin{array}{l}\text { Que las diferencias entre los sexos sean tomadas en cuenta } \\
\text { para brindar a las mujeres la oportunidad de aumentar sus sa- } \\
\text { larios y sus beneficios laborales, sugieren dar atención a esta } \\
\text { situación. } \\
\text { Discrepan en que los puestos sean solo ofertados para hombres, } \\
\text { aseguran que son abiertos a todos y todas. }\end{array}$ \\
\hline $\begin{array}{l}\text { Relaciones } \\
\text { entre } \\
\text { personal }\end{array}$ & $\begin{array}{l}\text { Solo las opiniones de que las mujeres son las únicas no } \\
\text { tomadas en cuenta es falso, también hay hombres que } \\
\text { son ignorados en algunas ocasiones en su ambiente } \\
\text { laboral. }\end{array}$ \\
\hline
\end{tabular}

Fuente: Elaboración propia. 


\section{HALLAZGOS DEL ACOSO/HOSTIGAMIENTO SEXUAL (A/HS)}

Los datos recogidos sobre la categoría "Acoso/Hostigamiento sexual" y sus respectivas subcategorías (conocimiento y percepción del tema, eventos de acoso y atención y seguimiento a denuncias), su sistematización y análisis condujeron a obtener lo siguiente.

\section{Categoría 1: Conocimiento y percepción del tema}

Antonio: Dentro de la capacitación [...] se le da especial importancia al tema del acoso y hostigamiento sexual y en este se tratan diferentes temas como lo son el evitar el flirteo con los compañeros, el habla soez, el lanzar piropos, pues, obviamente, lo que abarca los contactos físicos pues no apropiados y todo este tipo de conductas pues irreverentes e indebidas. [...] Últimamente pues esto se ha visto como algo más de procedimiento que de otra cosa, algo más rutinario; en realidad [...] se da por sentado que los trabajadores comprendieron y ya (Entrevista personal, 9 de mayo de 2017).

Héctor: Recuerdo que ya te había comentado que es un tema que se había mencionado en la certificación en la capacitación que nos habían dado. Yo como ingeniero manejo un equipo de trabajo y nos hacían mucha referencia a cómo escuchar a este tipo de problemáticas porque es algo que todavía se da y, definitivamente, nos hacían énfasis sobre todo en varios aspectos, por ejemplo, el evitar, pues como ya te comenté, el lenguaje ofensivo, el lenguaje sexual entre los compañeros y compañeras, evitar las relaciones amorosas, evitar cualquier maltrato incluso entre hombres y mujeres [...] hasta donde yo tengo entendido, recursos humanos es el encargado de estas capacitaciones; no sé si realmente [...] que alguien le exija a la empresa que esté certificada en este tipo de cuestiones [...] (Entrevista personal, 18 de mayo de 2017). 
César: Cuando yo entré a trabajar nos hablaron de esto en las pláticas, estas que te dan como capacitación. Fue así como por puntos que nos decían de no acosar a nadie, pero con más énfasis en el acoso hacia las mujeres. También tenía que ver no solo con acosar en forma de hablarles con lenguaje sexoso o vulgar, era sobre evitar tocar a cualquier persona o evitar tener estos acercamientos que pudieran terminar como situaciones de acoso sexual. [...] deberían ser más continuos con pláticas de esto [...] (Entrevista personal, 15 de mayo de 2017).

Cristina: Pues en la capacitación que te comenté al principio, ahí se le dio especial atención respecto a ese tema. Se nos dijo que nuestras formas de tratar a los demás debían de ser con mucho respeto principalmente, por ejemplo, al hablarnos entre compañeros no debía ser con palabras que fueran melosas, tampoco con mucha confianza o ser muy confianzudos entre nosotros y esas cosas; también se habló de no tocarnos innecesariamente, no ser vulgares, de no tener proposiciones que fueran indecorosas, pero, independientemente de la certificación, dentro de la política de la empresa ya existía que estaba prohibido tener relaciones amorosas dentro de la empresa incluso cuando se tiene familiares dentro de la empresa ya sea un hermano o hermana primo o prima etc. etc. [...] se nos dijo que el acoso sexual era un delito. [...]. (Entrevista personal, 15 de mayo de 2017)

Mila: Cuando yo entré a trabajar fue cuando nos explicaron todo esto del acoso sexual y de qué hacer en caso de sufrirlo. La plática nos la dio una trabajadora social y pues básicamente nos dijo que estaba altamente sancionado por la empresa y por las autoridades el que alguien fuera denunciando por incurrir en esta situación; básicamente todos tenemos que evitar conductas inapropiadas como lenguaje obsceno o que sea con el fin de incomodar a algún compañero o compañera. También hay que evitar pues insistir a una persona, sea hombre o mujer, con insinuaciones de índole sexual y ese tipo de cosas. Recientemente sí se nos dan pláticas, pero no tan extensas como en esa ocasión [...] (Entrevista personal, 3 de junio de 2017). 
En cuanto a la percepción de cuál sexo era más propenso o estaba en mayor riesgo de sufrir acoso sexual, se muestran algunos fragmentos.

Antonio: Te diría que por cuestión de números podría ser, pues el lado de las mujeres el que pudiera verse más expuesto que del lado masculino, y te lo comento porque es de mi conocimiento que son ellas quienes emiten más quejas o denuncias por algún tipo de acoso (Entrevista personal, 9 de mayo de 2017).

Héctor: Dentro de la empresa sí creo que una mujer tiene más riesgo de sufrir acoso (Entrevista personal, 18 de mayo de 2017).

Cristina: Pues podría parecer que sí, pero la verdad ahorita ya todos estamos expuestos. Los tiempos han cambiado mucho obviamente, pues empresas como estas quieren mantener su prestigio y evitar este tipo de escándalos por acoso y le dan más atención al género femenino que es el que siempre ha estado más expuesto [...] todos podemos ser víctimas de acoso ahorita; incluso yo he visto y me he enterado de casos donde las compañeras son las que acosan a los compañeros hombres (Entrevista personal, 15 de mayo de 2017).

Enriqueta: Nosotras estamos a expensas de todo, más en esta ciudad [...] Esto del acoso sexual es un problema grave, todos los días hay algo que nos afecta como mujeres, si yo que ya soy una señora tengo que aguantar a veces comentarios sobre la ropa o sobre cómo se me ve tal o cual cosa por parte de compañeros que son de este tipo, llevados, que no les importa no hacer estas cosas que finalmente son acoso, imagínese las muchachas más jóvenes lo que tienen que aguantar a diario [...] (Entrevista personal, 14 de mayo de 2017).

Mila: La verdad yo he visto situaciones de acoso tanto en mujeres como en hombres. Sí estamos más en riesgo nosotras, quién sabe por qué siempre nos va peor que a ellos y tenemos que lidiar con este tipo de cosas, pero pues, también hay compañeros que tienen que batallar con eso, sobre todo los guapos (ríe) o los que tienen 
puestos importantes porque pues es algo que pasa [...] O sea, ellos como que son más violentos con esto del acoso sexual, son más rudos y más desvergonzados que las mujeres que pudieran hacerlo; ellas o las que me ha tocado ver, incluso pudiera decirte 'ah no es acoso solo le está coqueteando", porque es menos agresiva su actitud que la de los hombres (Entrevista personal, 3 de junio de 2017).

Las siguientes respuestas refieren a la percepción de las y los entrevistados sobre las políticas de la certificación sobre la prevención del acoso sexual, si son suficientes para atender a esta problemática y si como trabajadoras y trabajadores se sienten protegidos de sufrir acoso sexual por contar con las mismas. Con sentido en lo anterior, las respuestas fueron las siguientes:

Héctor: No, yo pienso que, si la capacitación fue pobre, las políticas de prevención son todavía aún más pobres [...] Y pues de sentirme protegido y seguro (ríe), pues no realmente. Pues no, o sea, realmente esta capacitación o estas políticas no las toma uno en cuenta, es como si realmente no estuvieran ahí, realmente esto lo medito y lo pienso porque me estás entrevistando acerca de esto, pero realmente es un espectro que no se ve (Entrevista personal, 11 de mayo de 2017).

César: Mira sí hay políticas, sí está la certificación, sí se nos recuerda de vez en cuando sobre este tema, pero yo creo que hace falta insistir más en esto porque como te dije desde la primera vez que platicamos, esto ocurre a diario, tal vez no de maneras tan graves, pero sí es el pan de cada día lidiar con comentarios, acercamientos o chistes que no tienen nada de gracioso; principalmente las mujeres, pero pues también los hombres, las personas que tienen alguna diferencia, ya sea física o que vienen de otras partes del país y pues los que tenemos una orientación sexual diferente (Entrevista personal, 15 de mayo de 2017).

Cristina: Pues no, la certificación es una plática nada más, es el título, el papel donde se considera que hay control sobre este asunto, 
pero pues no se puede controlar completamente en ningún lado. Cuando un hombre quiere algo con una mujer lo busca, es por naturaleza o por instinto, se puede llamar como gustes y viceversa cuando una mujer quiere algo con un hombre ella lo busca y utiliza sus encantos, sus mañas como luego dicen para conseguirlo, entonces considero que no (Entrevista personal, 15 de mayo de 2017).

Enriqueta: Mire licenciada, la certificación es muy buena. Lo poco o lo mucho que yo sepa porque, pues realmente no soy experta en la materia, pero yo sí veo que hay información suficiente para prevenir estas conductas, pero también no se le da la importancia debida y suficiente porque mire, los manuales ahí están al alcance de todos, ahí está el reglamento, está la certificación, pero pues lamentablemente no se lleva a la práctica con la regularidad que se debería. Y pues, tanto protegida y segura definitivamente no, porque la certificación pudiera verse como un cuadrito en la pared ¿me explico? ¿Suena fuerte, verdad? Pero así es, honestamente hablando. Sí, sí hay sanciones y advertencias cuando ocurren estos casos, pero la verdad no evita que esto ocurra, licenciada, sigue ocurriendo día tras día. Se nos sigue acosando, se nos sigue tratando como inferiores, cosa que la certificación no evita del todo y eso pasa todos los días [...] (Entrevista personal, 14 de mayo de 2017).

Mila: Tanto como sentirme protegida al cien por ciento realmente no. O sea sí están todas estas cosas que dicen que no debe existir el acoso sexual en la empresa, pero pues sí pasa, a mí me pasó y la verdad fue muy duro tener que enfrentar esta situación y estar con el temor de que algo peor me pasara o incluso perder mi trabajo. No quiero verme como que estoy atacando a la empresa o que crea que la certificación y los demás reglamentos que existen para prevenir estas situaciones no sirven para nada en absoluto; más bien, hace más falta que se exponga y se le haga ver a todos los que trabajamos como un tema demasiado importante y que las consecuencias son graves y que nadie está exento de pagar por sus acciones (Entrevista personal, 3 de junio de 2017). 
El siguiente apartado da cuenta de los eventos de acoso que las y los entrevistados consintieron compartir.

Categoría 2: Eventos de acoso

Antonio: Pues sí, desgraciadamente sí me ha ocurrido. Fíjate que hasta pudiera pues hasta escucharse tonto para la mayoría de las personas de que un hombre sea acosado por una mujer, porque siendo honestos pues, no se escucha casi la verdad esta situación contraria a lo que sucede [...] yo la consideraba como una compañera amable [...] Esto me empezó a ocasionar problemas con mi esposa en mi vida privada y, claro, a quién no le hubiera ocasionado problemas que una persona del trabajo [...] te marque a tu casa y te mande mensajes [...] se lo expliqué a mi esposa y luego hablé con mi compañera [...] el problema persistió, eso fue lo que estuvo pasando (Entrevista personal, 9 de mayo de 2017).

Héctor: Sí, en una ocasión sí pasé un episodio de acoso. Realmente fue algo curioso, yo no lo veía como acoso, pero después me di cuenta que sí era algo que podría causarme problemas, porque la gente empezó a hablar mucho de esta situación... que una de mis trabajadoras me acosaba y pensaban que teníamos una relación por la manera de comportase conmigo, de ella. [...] al principio no me di cuenta [...] todo el mundo empezó a hacer especulaciones y después me di cuenta, porque soy un poco ingenuo, que las cosas iban hacia otro rumbo (Entrevista personal, 11 de mayo de 2017).

César: En mi caso pasó que, pues cierto día mi pareja me dejó en la entrada del edificio de la maquila y alguien vio que nos despedimos de beso. Ahí empezó mi problema, porque hasta ese día, pues yo había mantenido mi vida privada así, privada, y no había comentado con nadie mi orientación sexual ¿y por qué hacerlo no? Total que esta persona que vio lo que pasó, pues esparció esta información entre los compañeros y ahí empezó mi problema [...] los compañeros que antes se llevaban hasta de "compa" y "wey" conmigo, pues ahora como que tomaban su distancia [...]. Otras incluso también en son 
de broma me decían que "qué lástima Inge usted tan guapo" o "yo se lo quito Inge es que no ha estado con una mujer de verdad", ese tipo de comentarios que si bien no eran groseros, pues me incomodaban. A lo mejor no es como algo precisamente de ser acosado sexualmente, pero para mí era acoso y homofobia [...] (Entrevista personal, 18 de mayo de 2017).

Cristina: Pues mira, yo tenía un compañero, este era mi supervisor de área. Siempre fue un señor muy amable, caballeroso atento y en general con todos, no solo conmigo. Al principio yo no noté que me diera algún trato especial [...] Ya con el tiempo el supervisor pues, su trato era evidente verdad, y yo no lo veía. Las que se dieron cuenta fueron mis compañeras [...] pasó de ser la persona más amable del mundo a la más insistente que podría existir. A mí su actitud me empezó a molestar mucho y su insistencia [...] Perdóname, es que me acuerdo y me da mucha impotencia y rabia y coraje todavía, fue una situación muy difícil (Entrevista personal, 18 de mayo de 2017).

Enriqueta: Yo presencié y me vi involucrada en una situación delicada y difícil, y fue precisamente por acoso sexual. Mira te cuento que había una chica bastante joven que entró como operadora [...] en esa ocasión pues me voy dando cuenta de que este señor que era nuestro supervisor le manda llamar y le dice que está enterado de que sus papeles, su acta de nacimiento está alterada [...] esta muchachita me lo platicó llorando licenciada, que el supervisor le dijo que ella [...] podía ir a la cárcel [...] Este hombre escuchó la historia de esta joven y para no denunciarla, pues fijate, ella tenía que acceder a sus propuestas sexuales y esta niña pues se negó verdad, lo normal. [...] ella me dijo que no quería perder su trabajo y menos ir a la cárcel, pero tampoco quería acceder a las propuestas de este viejo, y pues yo tenía, yo sentía que yo tenía el compromiso moral con esta muchachita y pues acudí a recursos humanos (Entrevista personal, 14 de mayo de 2017). 
Finalmente, se cuestionó a las y los entrevistados sobre las medidas que tomaron para resolver su problemática de acoso, así como la atención que recibieron a sus denuncias.

Categoría 3: Atención y seguimiento a denuncias

Antonio: Bueno, pues yo acudí a recursos humanos, como era de esperarse pues... no se pudo resolver de la manera pacífica y sin consecuencias. Tuve que levantar un acta administrativa para que se le diera seguimiento a este caso y pues estar más tranquilo, estar sin esa presión de hostigamiento que ella estaba ejerciendo sobre mí. Te puedo decir que sí se resolvió mi caso [...] Afortunadamente mi compañera comprendió la situación con una llamada de atención y no pasó a mayores [...] En recursos humanos [...] te hacen una serie de preguntas para determinar si lo que está sucediendo es acoso o no, luego de eso, si no se tiene suficiente información para considerarlo acoso, pues se pide algún tipo de prueba o algunos testimonios que puedan avalar que tú estás diciendo la verdad [...] Ya que se considere así, se habla con la persona para preguntarle si es cierto que está pasando todo esto y cómo has de entender lo que sigue... si se niega o no se niega, se siguen ciertos pasos (Entrevista personal, 9 de mayo de 2017)

César: Cuando yo me harté de esta situación fui con el chisme (ríe). No ya hablando en serio, discúlpame es que estoy algo nervioso, pero ya hablando en serio, pues me quejé en recursos humanos e incluso me pasaron a hablar con la trabajadora social porque la verdad yo estaba muy mal [...] Así que presento esta queja y me piden señalar específicamente quiénes sentía yo que me molestaban más, así que di nombres y les mandaron llamar. Yo no sé qué les dirían, pero se calmaron (Entrevista personal, 15 de mayo de 2017).

Cristina: Pues efectivamente fui, me presenté en el departamento de recursos humanos y de ahí me mandaron al departamento de trabajo social, ahí es donde se encargan de darle seguimiento a estas denuncias. Pues expuse toda la situación, toda tal cual pasó, entonces 
se levantó un acta administrativa por acoso sexual y también por hostigamiento, y ya ellos quedaron en hablar con esta persona y pues resolver este problema [...] la verdad siento que sí le dieron la atención correcta a mi caso, porque se le dio atención inmediata al problema y afortunadamente yo ya no tuve que pasar más por esta situación, así que yo quedé muy conforme (Entrevista personal, 15 de mayo de 2017).

Enriqueta: Definitivamente sí creo que se atendió de forma adecuada. Este personaje ya tenía antecedentes verdad, de situaciones parecidas, entonces pues esto tuvo más peso en la acusación que se le formuló a él. Se le hizo también un acta administrativa, quiere decir que pues se hizo un reporte detallado de la situación y pues a él se le sancionó en su salario porque ya tenía advertencias por conducta inadecuada, pero pues finalmente le dijeron que estaba en riesgo de ser despedido si continuaba con estas acciones (Entrevista personal, 14 de mayo de 2017)

Mila: Yo tenía mucho miedo de decir la verdad, lo que estaba ocurriendo por temor de que él se enojara más y empeoraran más las cosas, pero la verdad yo no podía continuar con esta situación de tener miedo de hasta ir al baño o al estacionamiento yo sola, así que puse mi denuncia en recursos y de ahí le dieron seguimiento a mi caso. [...] A él se le sancionó en su expediente y con multa salarial y con un acta administrativa por acoso y conducta violenta con la advertencia de despido en caso de que yo volviera a quejarme de él. Afortunadamente eso bastó para que ya ni siquiera se topara conmigo (Entrevista personal, 5 de junio de 2017).

En síntesis, la agrupación de respuestas sobre acoso, sugiere el siguiente contenido (Figura 4). En cuanto al conocimiento del tema, en efecto, el grupo de personas entrevistadas reconoce la preocupación por la parte empleadora de abordar el acoso y el hostigamiento entre su plantilla. En general, se aprecia que esas prácticas constituyen una expresión de la violencia de género que 
cuando se experimentan generan daños en lo individual, en lo familiar, así como en el ambiente laboral.

El grupo de personas que han experimentado situaciones de acoso sexual u otras conductas violentas han reconocido vivir situaciones de conflicto donde su integridad física, psíquica, moral, social, su dignidad y sus derechos humanos se han perturbado.

En este sentido, la parte agresora sí ha ejercido "su abuso de poder" bajo cierto patrón de conducta (verbal, física, con connotación lasciva) que ha intimidado a la víctima, propiciando cuestionamientos en torno a decidir si procedía tolerar más eventos, magnificando soportar un ambiente laboral hostil o si lo más conveniente era presentar la denuncia correspondiente atendiendo las normas o protocolos establecidos desde y dentro de la empresa.

Ante estas circunstancias, tal como sugiere la Comisión Nacional de Derechos Humanos (2018) en México, las prácticas de hostigamiento o acoso sexual que tienen lugar en las empresas (o fuera de ellas) violentan una amplia lista de derechos humanos de las víctimas (derecho a la vida, derecho a la integridad física, derecho a la integridad psicológica, derecho a la libertad sexual, derecho a el libre desarrollo de la personalidad, derecho al trabajo, derecho a un ambiente laboral sano, entre otros) por lo que constituyen temas que procede no minimizar.

Entre los costos que pueden identificarse como producto de las experiencias de acoso sexual vividas y compartidas por las personas entrevistadas se visualiza que de alguna manera padecieron: sufrimiento psicológico, cambios de comportamiento, deterioro en sus relaciones sociales, enfermedades mentales, riesgo de pérdida de trabajo, disminución en la productividad, desmotivación, por mencionar algunos. 
Figura 4. Acoso/Hostigamiento sexual.

\begin{tabular}{|c|c|}
\hline Categoría & Concordancias \\
\hline $\begin{array}{l}\text { Conocimiento y } \\
\text { percepción del } \\
\text { tema }\end{array}$ & $\begin{array}{l}\text { El tema del acoso sexual se aborda con mayor énfasis al } \\
\text { momento de ingresar a trabajar a la empresa. } \\
\text { La continuidad que se da para tratar este tema se va ami- } \\
\text { norando conforme pasa el tiempo. } \\
\text { Las mujeres están en mayor riesgo de sufrir acoso que los } \\
\text { hombres. } \\
\text { Mujeres y hombres pueden ser acosados. } \\
\text { La manera en que acosan hombres y mujeres es diferente. }\end{array}$ \\
\hline $\begin{array}{l}\text { Eventos de } \\
\text { acoso }\end{array}$ & $\begin{array}{c}\text { Todos y todas atravesaron alguna situación de acoso o se } \\
\text { vieron involucrados en alguna situación relacionada. } \\
\text { Para todos y todas fue una situación altamente incómoda, } \\
\text { indeseable e inaceptable. }\end{array}$ \\
\hline $\begin{array}{l}\text { Atención y } \\
\text { seguimiento a } \\
\text { denuncias }\end{array}$ & $\begin{array}{l}\text { Sus denuncias fueron atendidas y solucionadas satisfacto- } \\
\text { riamente. } \\
\text { Las sanciones impuestas a sus acosadores(as) son consi- } \\
\text { deradas como aceptables. } \\
\text { La respuesta del departamento encargado de dar segui- } \\
\text { miento y atención a sus quejas es descrita como buena y } \\
\text { adecuada. Aunque es cuestionado el proceso de increduli- } \\
\text { dad por la parte acosada. }\end{array}$ \\
\hline Categoría & Discordancias / Sugerencias del tema \\
\hline $\begin{array}{l}\text { Conocimiento y } \\
\text { percepción del } \\
\text { tema }\end{array}$ & $\begin{array}{l}\text { Las mujeres son las únicas acosadas, es falso. } \\
\text { Sugieren que debe hablarse más ampliamente sobre el } \\
\text { acoso sexual hacia los hombres y cómo se percibe a estos. }\end{array}$ \\
\hline $\begin{array}{l}\text { Eventos de } \\
\text { acoso }\end{array}$ & $\begin{array}{c}\text { La manera en que realizan sus denuncias: los hombres no } \\
\text { denunciaron hasta que se convirtió en un problema que } \\
\text { ponía en riesgo a su familia o su trabajo. } \\
\text { Las mujeres denunciaron inmediatamente. }\end{array}$ \\
\hline $\begin{array}{l}\text { Atención y } \\
\text { seguimiento a } \\
\text { denuncias }\end{array}$ & $\begin{array}{l}\text { El tipo de acoso que ejercen las mujeres no es considera- } \\
\text { do propiamente como acoso sexual. } \\
\text { Se requiere dar importancia a otras formas de acoso, no } \\
\text { solo de naturaleza sexual. El acoso laboral o verbal, psico- } \\
\text { lógico requiere atención. }\end{array}$ \\
\hline
\end{tabular}

Fuente: Elaboración propia. 
Por lo anterior, y para concluir este apartado, resta agregar que la segregación laboral por razones de género y el acoso sexual son temas que generan escozor e incomodidad en el ambiente laboral. Un aprendizaje obtenido es que las y los entrevistados pasaron por un proceso de reflexión que les permitió reconocer cómo hacer frente al ambiente laboral hostil y que, a pesar de haber sufrido momentos difíciles, las acciones de enunciar hechos y sentimientos sirvieron como una alerta para tener con otros compañeros y compañeras conversaciones sobre la importancia de denunciar cualquier situación que ponga en riesgo su seguridad dentro y fuera del área de trabajo. Al mismo tiempo, tuvieron que superar barreras, temores y creencias para garantizar la vigencia de sus derechos. Para finalizar, se listan enseguida algunos comentarios finales a manera de conclusiones.

\section{CONCLUSIONES}

La certificación en el Modelo de Equidad de Género contempla diversos temas y categorías de análisis. En este caso, el análisis se enfocó en la segregación laboral por razones de género y el acoso/hostigamiento sexual. Una justificación que le dio cabida a abordar este problema en Ciudad Juárez fue que desde los años sesenta y hasta la década de los 2000, los estudios relacionados con la industria maquiladora, la segregación ocupacional o laboral ocupó un lugar prioritario en materia de investigación. Posteriormente, las condiciones económicas obligaron a que los temas principales se centraran en rotación de personal, el desempleo, las condiciones de precariedad de los empleos o en la inestabilidad laboral de la población ocupada.

En la actualidad, según las orientaciones emitidas por una parte dictaminadora de este estudio, atinadamente advirtió que el contexto del T-MEC y las obligaciones dispuestas por los convenios y directrices de la Organización Internacional del Trabajo hacia los estados sugieren poner en el centro de la discusión el sector maquilador y las diversas aristas que de ahí se derivan.

La acción de recuperar las experiencias de acoso/hostigamiento sexual $(\mathrm{AS})$ y la segregación laboral por razones de género 
(SLRG) de las y los trabajadores que laboraban en una empresa maquiladora certificada en el Modelo de Equidad de Género (MEG) en 2017 llevó a contemplar que la observación, seguimiento y análisis de las experiencias manifestadas por las personas entrevistadas resultan de gran valor. Los estudios de carácter cuantitativo se advierten limitados en su interpretación por lo que se optó por asumir un estudio de tipo cualitativo. La implementación del MEG en la empresa maquiladora estudiada en Juárez confirma que una certificación demanda acciones y estrategias.

En términos teóricos, la articulación de ideas propuestas por la corriente del feminismo marxista admite afirmar que la estructura económica que da soporte a la producción no es el elemento exclusivo para la comprensión de experiencias sobre AS y SLRG. El hecho de que las mujeres, o bien los varones, decidan "emanciparse" a través de emplearse en un trabajo remunerado, o decidan controlar la fertilidad, combinar actividades domésticas con las laborales, considerar que el amor es uno de sus pilares emocionales y humanos, cuestionen su posición jerárquica en el plano laboral, atiendan responsabilidades individuales, familiares o laborales, resuelvan sus necesidades humanas en condiciones más equitativas, implica la presencia de dilemas, disyuntivas que requieren estudiar las dimensiones de la vida social en función de abordarlas desde una perspectiva más humana, transversal y esclarecedora.

Queda claro que los cambios en las condiciones de producción y reproducción de las familias han demandado la reducción de tiempo disponible para atender actividades no remuneradas por parte de los jefes y jefas de familia, pero ello no ha garantizado el acceso a puestos jerárquicos mejor remunerados; por lo que queda pendiente seguir estudiando a qué se debe la inequidad que persiste en el trabajo o en los hogares compuestos por hombres y mujeres.

Del mismo modo, en cuanto al entorno laboral, se pone de manifiesto que el lugar de trabajo sí constituye una plataforma donde las relaciones interpersonales pueden propiciar situaciones de acoso sexual, hostigamiento sexual y segregación laboral que atentan contra la dignidad de las personas y sus derechos humanos. 
En el caso de los supuestos, se confirmó que el hecho de que una empresa esté certificada en el MEG en México no es garantía para que el acoso sexual o la segregación laboral sean prácticas eliminadas o erradicadas. En efecto, las mujeres entrevistadas sugirieron que ellas son más acosadas sexualmente, más segregadas y mayormente discriminadas en comparación con sus compañeros hombres.

Se reconoce que los hombres son acosados, pero en menor magnitud y en forma distinta a las mujeres. Los varones entrevistados indicaron no sufrir de acoso sexual con la misma frecuencia que sus compañeras mujeres. Sin embargo, independientemente de que unas y otros sean acosados(as) u hostigados sexualmente -o que sean testigos de algún acto similar-, sucede que a tanto a unos como a otras les resulta difícil hacer frente a este tipo de eventos.

Las y los entrevistados concordaron en que son las mujeres quienes están en mayor riesgo de sufrir acoso sexual y que cuando ocurre hacia los varones no se percibe como tal hasta que les supone un problema que pueda generarles consecuencias negativas en lo personal, lo familiar y en lo laboral.

Las acciones de las mujeres acosadoras pueden no ser entendidas como acoso sexual, sino que sus prácticas se denominan coquetería o "actuaciones propias" de su condición de género. En cambio, si un hombre acosa se considera directamente un delito. Las empresas certificadas bajo el Modelo de Equidad de Género prioritariamente deben procurar entre sus trabajadoras y trabajadores que se prevenga y evite cualquier tipo de conducta que sea catalogada como acoso u hostigamiento sexual y ello requiere monitorear atentamente lo que ocurre dentro de la organización como fuera de ella.

Al parecer, las mujeres de la empresa tienen menor acceso a puestos de trabajo de mayor nivel y a menores salarios mientras que la voz de los varones tiene mayor peso y credibilidad al interior de la empresa; aunque, ocurre que las decisiones en ocasiones son unilaterales y tomadas por el personal que ocupa los altos mandos. En general, se aprecia que cuatro factores determinan 
que las mujeres sufran mayor segregación laboral por razones de género versus los varones: sexo, tiempo disponible, edad y puesto.

Sin duda, el Modelo de Equidad de Género permite monitorear las circunstancias que dan soporte a estrategias a favor de la equidad y la igualdad de oportunidades en las empresas y su planta laboral. El desacierto en ese modelo es que es un mecanismo que admite que las empresas u organizaciones soliciten de manera "voluntaria" su proceso de evaluación, al igual que ocurre con la ahora denominada Norma Mexicana NMX-R-025-SCFI en igualdad laboral y no discriminación (NMX), cuya ejecución está a cargo de un consejo interinstitucional conformado por la Secretaría del Trabajo y Previsión Social (STPS), el Inmujeres y el Consejo Nacional para Prevenir la Discriminación (Conapred).

En lo sucesivo, procede considerar por los organismos certificadores que la evaluación sea obligatoria y que el monitoreo de datos cuantitativos se complemente con informes de índole cualitativa para documentar de qué manera es más sencillo y viable que las organizaciones propicien climas laborales libres de violencia de género, de forma que puedan promoverse mejores relaciones de trabajo y ambientes a favor de la equidad y de la igualdad de oportunidades.

En cuanto a las limitaciones de este trabajo cabe enunciar las siguientes: la disponibilidad de recursos financieros, recursos humanos y el tiempo constituyeron restricciones que influyeron en el trabajo de campo. El Modelo de Equidad de Género se considera una estrategia adecuada e importante para definir acciones a favor de las relaciones en el sistema sexo-género como en el entorno laboral, mas debido a que es un programa público delineado desde la esfera gubernamental implicó que su vigencia fuera limitada; de modo que el estudio de los impactos o alcances fueron interrumpidos.

En definitiva, los resultados y hallazgos sugeridos por esta investigación permiten trazar diversas líneas de trabajo vinculadas con modalidades asociadas con la certificación en las empresas con componentes de género, definir estrategias para evitar la discriminación de género, ahondar en los mecanismos vinculados 
con la segregación laboral por razones de género, estipular acciones o manuales de buenas prácticas para denunciar acoso y hostigamiento sexual, sugerir estudios que profundicen el abordaje de la NMX, financiar proyectos que monitoreen los ODS del PNUDNaciones Unidas, y en concreto el objetivo número 5 (Lograr la igualdad entre los géneros y empoderar a todas las mujeres y las niñas para evitar ambientes de violencia y discriminación en el mundo).

Asimismo, se requiere estudiar los marcos normativos internacionales o legislaciones regionales, códigos de trabajo e inclusive códigos penales vinculados con la violencia de género, la discriminación, la segregación, el acoso o el hostigamiento sexual, de forma que se emitan recomendaciones y resoluciones a favor de ambientes y condiciones laborales sanas.

Por último, una propuesta que considerar para atender desde la academia el abordaje de estos temas sugiere destinar especialistas para integrar contenidos educativos en la modalidad de seminarios, diplomados, cursos, cursos en línea de educación abierta y masivos (MOOC o CEMA), podcasts, entre otros, con miras a sugerir soluciones, protocolos y buenas prácticas que erradiquen la segregación laboral, eviten la promoción de ambientes laborales nocivos y, con ello, se promueva la equidad de género.

\section{BIBLIOGRAFÍA}

Anker, R. (1997). "La segregación profesional entre hombres y mujeres. Repaso de las teorías”. Revista internacional del trabajo; vol. 116, núm. 3. Ginebra.

Bordieu, P. (1986). Teoría de los campos sociales. ARSS.

Colín, M. (2010). Trayectorias laborales diferenciadas y segregación laboral de género en instituciones públicas. México.

Comisión Nacional de Derechos Humanos, CNDH (2017). Hostigamiento sexual y acoso sexual. CNDH. Primera edición. México. Creswell, J. (1998). Diseño de investigación. Aproximaciones cualitativas y cuantitativas. Sage. 
Denzin, N., \& Lincoln, Y. (2015). Manual de investigación cualitativa, Vol. IV: Métodos de recolección y análisis de datos. Buenos Aires, Argentina: Gedisa.

Espasandín, María C. (2018). Articulaciones entre marxismo y feminismo: ayer y hoy, en R. Katál, Florianópolis, vol. 21, núm. 3, p. 584-593, DOI: http://dx.doi.org/10.1590/1982-02592018v2n30584 Ferrer Pérez, V. A. y Bosch Fiol, E. (2006). "El papel del movimiento feminista en la consideración social de la violencia contra las mujeres: el caso de España”, en Revista Digital de Estudios Feministas, dossier núm. 10.

Giménez, M. y Vogel, L. (2005). "Marxist-feminist thought today". Science and society, 69. USA.

Hernández, R. (2007). Buenas prácticas de gestión escolar. Lecciones desde la evaluación cualitativa PEC. IX Congreso Nacional de Investigación Educativa, (págs. 1-12). México.

Hernández, R., Fernández, C., \& Baptista, P. (2010). Metodología de la Investigación (6a ed.). México: Mc Graw Hill Education.

Inmujeres, Instituto Nacional de las Mujeres (2015). Nuestra empresa es la igualdad. Modelo de equidad de género, MEG. Gobierno federal. México. www.Inmujeres.gob.mx.

Inmujeres, Instituto Nacional de las Mujeres (2017). Acciones y programas. Modelo de equidad de género. Disponible en https://www.gob.mx/Inmujeres/acciones-y-programas/modelode-equidad-de-genero-2003-2015. Consultado el 18 de agosto de 2017.

Kanter, R. (1997). On the frontiers of management. Boston, Harvard Bussines Press. NY, basic books.

López, M., Nicolás, C., Riquelme, P. y Ramírez, N. (2019). Análisis de la segregación ocupacional por género en España y la Unión Europea (2002-2017) en Prisma Social, Revista de Ciencias Sociales, núm. 26. pp. 159-182.

Norma Mexicana en Igualdad Laboral y No Discriminacion-2015 (NMILND-2015), (Norma Mexicana en Igualdad Laboral y No Discriminación, 2015). Disponible en https://www.gob.mx/ Inmujeres/acciones-y-programas/norma-mexicana-nmx-r025-scfi-2015-en-igualdad-laboral-y-no-discriminacion. 
Patton, M. (2002). Qualitative research. Gae Sanit editors. USA. Riquer, F. (2005). "Del movimiento feminista a la institución: ¿una historia que aún no puede contarse?" Cuadernos de la sociedad civil, 10, Xalapa: Universidad Veracruzana.

STPS, Secretaría del Trabajo y Previsión Social (2017). NMX-R-025SCFI. https://ww.gob.mx/stps.

Taylor, S. J., Bogdan, R. (1992). Introducción a los métodos cualitativos en investigación. Ed. Paidós. España. 